Revista de Ensino em Artes, Moda e Design

Dossiê 5

As fontes de pesquisa para moda. Uma aproximação interdisciplinar e arquivista da história da moda: pesquisa e ensino.

DOI: $10.5965 / 25944630332019054$

\title{
FONTES PARA O ESTUDO DA JOALHERIA DO SÉCULO XIX: AS EXPOSIÇÕES UNIVERSAIS
}

\section{Sources for the study of 19th Century Jewelry: The International Exhibitions}

\section{Sources pour l'étude des bijoux du XIXe siècle: Les Expositions Universelles}

\author{
Valesca Henzel Santini ${ }^{1}$ \\ Heloisa Barbuy²
}

\footnotetext{
1 Possui graduação em Arquitetura e Urbanismo pela Universidade do Vale do Rio dos Sinos-UNISINOS (1997) e graduação em Museologia pela Universidade Federal do Rio Grande do Sul-UFRGS (2012). Mestre em Ciência da Informação pela Universidade Federal do Rio Grande do Sul-UFRGS (2012), atualmente é doutoranda no Programa de Pós-Graduação em História Social da Universidade de São Paulo-USP. Atua desde 2013 como Especialista em Pesquisa e Documentação de Coleções no Museu Paulista da Universidade de São Paulo. E-mail: vhsantini@usp.br | Lattes: http://lattes.cnpq.br/5413318365304530 | Orcid: http://orcid.org/0000-0003-0243-8586
} 


\section{Resumo}

Este artigo busca identificar as contribuições das Exposições Universais para a disseminação de padrões na joalheria da segunda metade do século XIX, posto que tais eventos foram palco para demonstrações dos ideais de progresso e avanços tecnológicos vigentes no século XIX, além de terem sido o espelho dos valores e gostos da elite da Europa oitocentista. Analisaremos, sob a perspectiva da Cultura Material, considerando a produção, circulação e usos dos objetos, documentos textuais e visuais das Exposições Universais realizadas em Londres em 1851 e 1862, bem como da Exposição de Paris de 1889. A partir dos relatórios do júri buscaremos identificar quais foram os critérios utilizados para a escolha das joias premiadas em cada Exposição, bem como quem eram os principais joalheiros expositores e suas características. A partir dos catálogos e jornais ilustrados das Exposições buscaremos compreender a visualidade das joias, formas e materiais. Ao utilizarmos as Exposições Universais como fonte para o estudo da joalheria, pretendemos contribuir para uma aproximação interdisciplinar do estudo da história da moda.

Palavras-Chave: Joalheria. Exposições Universais. Cultura Material.

\section{Summary}

This article seeks to identify the contributions of the International Exhibitions to the dissemination of patterns in the second half of the 19th century Jewelry, given that those events were the stage for demonstrations of the ideals of progress and technological advances prevailing in the 19th century, in addition to having mirrored the values and tastes of the elite of nineteenth-century Europe. We will analyze, from the perspective of Material Culture, textual and visual documents considering the production, circulation and use of objects of the International Exhibitions held in London in 1851 and in Paris in 1889. From the jury reports we will seek to identify which were the criteria used to choose the awarded jewels in each Exhibition, as well as who were the main exhibiting jewelers and their characteristics. From catalogs and illustrated newspapers of the Exhibitions we will try to understand the visuality of the jewels, shapes and materials. By using the International Exhibitions as source for the study of Jewelry, we intend to contribute to an interdisciplinary approach to the study of the history of Fashion.

Key words: Jewelry. International Exhibitions. Material Culture.

\section{Resumé}

Cet article cherche à identifier les contributions des expositions universelles pour la diffusion des tendances dans l'industrie de la bijouterie de la seconde moitié du XIXe siècle, étant donné que tels événements ont représenté une étape de la démonstration des idéaux de progrès et des avancées technologiques du XIXe siècle, en plus d' avoir été le réflexe des valeurs et des goûts de l'élite européenne du même siècle. Du point de vue de la culture matérielle et considérant la production, la circulation et l'utilisation d'objets, nous analyserons des documents textuels et visuels issus des expositions universelles organisées à Londres en 1851 et 1862, ainsi que ceux de l'Exposition de Paris de 1889. À partir des rapports du jury nous essaierons d'identifier les critères utilisés pour choisir les prix décernés lors de chaque exposition, ainsi que les principaux bijoutiers exposants et leurs caractéristiques. Selon les catalogues et quelques journaux illustrés des expositions, nous tenterons de comprendre les aspects visuels des bijoux, leurs formeset les matériaux choisis pour les fabriquer. En utilisant les expositions universelles comme source d'étude des bijoux, nous entendons contribuer à une approche interdisciplinaire de l'étude de l'histoire de la mode.

Mots-clés: Bijoux. Expositions Universelles. Culture Matérielle. 


\section{INTRODUÇÃO}

Frédéric Boucheron, fundador da famosa joalheria francesa que leva seu nome, era filho de comerciantes de tecidos. Inspirado na delicadeza dos materiais têxteis, começou, ainda muito jovem, a fabricar joias de ouro tão flexíveis quanto as rendas da sua infância. Ele seria o primeiro joalheiro a abrir loja na Place Vendôme, em Paris, em 1893, local que iria reunir todas as maiores casas da alta joalheria mundial'1.

Apesar da intersecção entre indumentária e joalheria aparecer de forma clara no universo da moda, o mesmo não ocorre na esfera acadêmica. Costuma-se encontrar referências à joalheria em pesquisas no campo da indumentária e da moda, porém isso ocorre, em geral, de forma acessória ou secundária. De fato, uma das funções da joia é complementar a indumentária, exercendo, por vezes, o papel de prender partes da roupa, como no caso de botões, fivelas ou alfinetes, e é certo que as joias, assim como as roupas, também têm seus ciclos, ainda que menos efêmeros, e mudam ao longo do tempo de acordo com os gostos e os recursos tecnológicos. Algumas peças da chamada joalheria de indumentária ${ }^{2}$ se transformaram ao longo do tempo, acompanhando a mudança da moda. Foi o caso dos chamados Stomachers ou Devant de Corsage, que foram criados para cobrir a frente dos corpetes e tornaram-se populares ainda no século XV. Estas peças foram mudando de forma e tamanho de acordo com o recorte dos vestidos, e caíram no esquecimento conforme desapareceram as linhas da cintura, para serem transformados em broches menores para serem usados na altura no peito.

Há na joia, porém, um valor de permanência incompatível com os rápidos ciclos característicos da moda. Tal afirmação fora feita pelo poeta francês Stéphane Mallarmé em 18743:

Eu aconselharia a uma senhora, que está indecisa quanto a quem confiar o desenho de uma joia preciosa, a pedir este desenho ao arquiteto que construiu sua casa, em vez de pedir à costureira ilustre que traz seu vestido de gala. Tal é, em uma palavra, a arte da joia. (MALLARMÉ, 2016, p. 275).

A partir do sentido de permanência a que se refere Mallarmé, abordaremos neste artigo as fontes para o estudo da joalheria ${ }^{4}$, colocando foco nas contribuições das Exposições Universais para o tema da joia do século XIX. A partir de documentos oficiais das Exposições Universais e da vasta bibliografia produzida sobre o tema, buscaremos identificar os padrões de joias apresentadas naqueles eventos, que acreditamos ser o espelho dos valores reinantes na época. Nossa abordagem será feita sob a perspectiva da Cultura Material, que Thomas Schelereth definiu como "Vasto universo de objetos usados pela humanidade para lidar com o mundo físico, para facilitar a vida social e para criar símbolos e significados." (SCHELERETH, 1985, p. 13, tradução nossa). Não se trata, porém, dizem Julien e Rousselin, de reduzir o objeto à coisa em si. O que interessa ao campo da Cultura Material é a integração entre o sujeito e o objeto, incluídos aí os gestos que envolvem a execução do objeto, que também estão ligados à construção da cultura.

\footnotetext{
1 Localizada no IX arrondissement de Paris, a concepção da Place Vendôme data de 1699, porém foi a partir de 1893 que começou a tornar-se polo da alta joalheria. Fonte: https://us.boucheron.com/en_us/the-maison/history.html

20 termo joalheria de indumentária é utilizado por Gonçalo de Vasconcelos e Souza.

30 texto do poeta Stéphane Mallarmé foi publicado pela Revista dObra(s) em 2016, com tradução de Izabella Haddad. https:// dobras.emnuvens.com.br

4 Este artigo é parte de nossa pesquisa de doutorado, cujo tema é a produção, circulação e usos da joia no século XIX em São Paulo, atualmente em andamento no Programa de Pós-Graduação em História Social da USP, sob orientação da Prof. Dra. Heloisa Maria Silveira Barbuy.
} 
A construção da cultura material depende da extrema diversidade de atores que a compõem: as condições de produção social, econômica e política do objeto como portadores de significados, bem como, os espaços sociais de sua produção. (JULIEN; ROSSELIN, 2005, p. 6, tradução nossa).

A pesquisa em Cultura Material pressupõe olhar o objeto em seus diferentes aspectos: produção, circulação e uso, e para isso é indispensável a utilização de diferentes fontes, como diversos fios que se entrelaçam formando uma trama com significado coerente. Para Ulpiano Bezerra de Meneses, nenhum atributo de sentido vem da própria materialidade. Estes atributos são selecionados pelos grupos que o fazem na sua produção, circulação e consumo, por isso, diz Ulpiano "[...] seria vão buscar nos objetos o sentido dos objetos." (MENESES, 1998, p. 91). A importância da compreensão da materialidade reside em permitir que sejam feitas, através dela, inúmeras leituras sobre seu contexto, técnicas de fabricação e sinais de uso. Para isso, é imprescindível a convergência da utilização de fontes materiais, textuais e visuais.

No caso da joalheria do século XIX, as fontes materiais constituem, essencialmente, coleções de joias de acervos de museus, às quais o acesso costuma ser restrito, além de coleções particulares, na maioria das vezes, inacessíveis à pesquisa. Através da análise material da joia identificamos as formas, os materiais, os tipos de lapidação das gemas e de cravação nos metais. Algumas vezes também é possível verificar nas peças as marcas de ourives e de contrastaria ${ }^{5}$, que fornecem a indicação de autoria e local da produção da peça.

As fontes textuais, por sua vez, nos trazem informações sobre o exercício da profissão dos ourives, comércio e ainda sobre posse e uso de joias. É o caso de inventários, testamentos, regimentos de profissão e registros de importação, além de romances, crônicas ou cartas que contenham descrições de tipos de joias utilizadas no século XIX. Já as fontes iconográficas nos dão pistas sobre o uso das joias, como no caso dos retratos, onde é possível observar como eram utilizados anéis, colares, pulseiras ou adereços de cabelo e de indumentária.

Na segunda metade do século XIX, as Exposições Universais tiveram grande importância para a disseminação de ideias, valores e gostos. Dedicaremos este artigo a analisar documentos textuais e visuais das Exposições Universais, buscando identificar suas contribuições para o universo da joalheria. Analisaremos, principalmente, relatórios e catálogos das duas exposições realizadas em Londres - 1851 e 1862, e da exposição de Paris de 1889, uma vez que julgamos terem sido estas as exposições que, do ponto de vista da joalheria, mais apresentaram novidades em técnicas e materiais. Não deixamos de contemplar, entretanto, informações relevantes de outras exposições, que permearão este artigo ${ }^{6}$.

\section{AS EXPOSIÇÕES UNIVERSAIS}

As Exposições Universais constituem um tema que conta, hoje, com uma bibliografia considerável e pesquisada em profundidade a partir das mais diferentes abordagens $^{7}$. Por essa razão, apresentaremos no presente artigo características gerais que

5 A função da marca de Contrastaria é atestar a qualidade do metal do qual a peça é feita. Cada centro produtor possui sua própria marca, em geral representada pelo desenho de um animal.

6 Além das Exposições analisadas, as principais exposições realizadas, ainda durante a segunda metade do século XIX, foram as seguintes: Paris, 1855; Paris, 1867, Viena,1873; Filadélfia, 1876; Paris, 1878; Chicago, 1893; Paris, 1900.

7 Sobre Exposições Universais, ver; Union Centrale des Arts Décoratifs (1983); Margarida Souza Neves (1986); Pesavento (1994); Schroeder-Gudehus e Rasmussen (1992), Ory (1982). 
consideramos necessárias para darem a dimensão da grandiosidade destes eventos, sua forma de organização e divulgação. Era a representação material da evolução tecnológica que o século XIX experimentava (BARBUY, 1999). Eventos grandiosos, de caráter comemorativo, que duravam aproximadamente seis meses, onde diversos países apresentavam ao mundo seus melhores produtos, invenções e avanços tecnológicos, competindo entre si pelas medalhas oferecidas àqueles que se destacassem. Receber uma medalha em uma Exposição Universal significava consolidar posição de destaque em seu segmento. Exibia-se uma profusão de produtos de todas as partes do mundo; de máquinas a chapéus, de algodão a diamantes.

Construíam-se verdadeiras cidades efêmeras, num misto de espetáculo com função didática, destinadas a ensinar a viver no mundo moderno. Para Pascal Ory (2010), as exposições universais se utilizaram de uma fórmula que cumpria as oito funções estabelecidas pelo autor: função de exibição; função econômica; função de feira comercial; função de exercício arquitetônico; função de alavanca urbanística; função de exposição de arte; função de festa de recepção oferecida pela potência anfitriã; função de sociedade das nações; e por fim, função de festa popular.

O legado arquitetônico e urbanístico das Exposições alcança a atualidade e demostra a dimensão daqueles eventos, marcadas por grandes obras modernas, como o metrô de Paris (primeiro metrô do mundo), construído para a Exposição de 1900, e a Torre Eiffel, erigida para a Exposição Universal de 1889.

As Exposições Universais eram eventos rigidamente regulamentados e organizados, e foram amplamente documentados, tendo deixado grande quantidade de registros oficiais, assim como crônicas e relatos variados, além de abundante iconografia.

Dentre as publicações oficiais, optamos por analisar os relatórios dos júris das classes de joalheria, buscando identificar quais critérios eram utilizados pelos jurados na avaliação das peças, quais joias eram premiadas, quem eram os expositores e os joalheiros, uma vez que os valores que norteavam as escolhas dos jurados seriam os mesmos que a elite europeia utilizava para eleger seus objetos de uso cotidiano, que espelhavam seu estilo de vida. Tais objetos, gostos e ideias eram disseminados internacionalmente através das pessoas que visitavam o evento e também através das imagens das Exposições, que circulavam pelo mundo. Em São Paulo, por exemplo, o jornal Correio Paulistano anunciava, em 1867, a exibição de imagens da exposição universal que estava sendo realizada em Paris naquele ano:

\footnotetext{
Pode-se viajar em Paris e ver todas as maravilhas da Exposição de 1867 com pouco dinheiro. A Casa Garraux recebeu uma esplêndida coleção de moderníssimas vistas fotográficas para estereoscópios, representando todas as maravilhas, as curiosidades, as belezas, os prodígios, fenômenos, raridades, da Exposição Universal de 1867, em Paris. (CORREIO PAULISTANO, 1867, edição 03472).
}

Os relatórios dos jurados trazem, em sua grande maioria, a descrição detalhada dos objetos premiados e uma explicação do motivo pelo qual o júri recomendou o prêmio, porém, sem referências de imagens das peças, recorremos, então, aos catálogos oficiais das exposições, já que estes, além da descrição do que eram consideradas as melhores peças da exposição, apresentam, também, ilustrações que muito nos auxiliam na compreensão dos objetos. 


\subsection{THE GREAT EXHIBITION OF THE WORKS OF INDUSTRY OF ALL NATIONS, LONDRES, 1851}

A primeira grande Exposição Universal do século XIX, denominada The Great Exhibition of the Works of Industry of All Nations, foi realizada em Londres em 1851, em uma grande estrutura de ferro e vidro construída no Hyde Park, contando com o apoio moral e financeiro da casa real britânica. Sandra Pesavento (1997) lembra que a Rainha Victoria comparou a inauguração de 1851 com a sua coroação, de acordo com os registros encontrados em seu diário. De maio a outubro daquele ano, cerca de 6 milhões de visitantes estiveram no Crystal Palace, construído no Hyde Park para abrigar os 14 mil expositores, que apresentaram 30 classes de produtos, distribuídos em 4 grandes grupos: 1) Produtos brutos; 2) Máquinas; 3) Produtos manufaturados; 4) Belas Artes. Neste sistema classificatório, encontramos o setor de joalheria no grupo de produtos manufaturados, na Classe XXIII - Works in precious metals, jewellery, articles of virtu.

Figura 1: Abertura da Exposição Universal de 1851, em Londres.

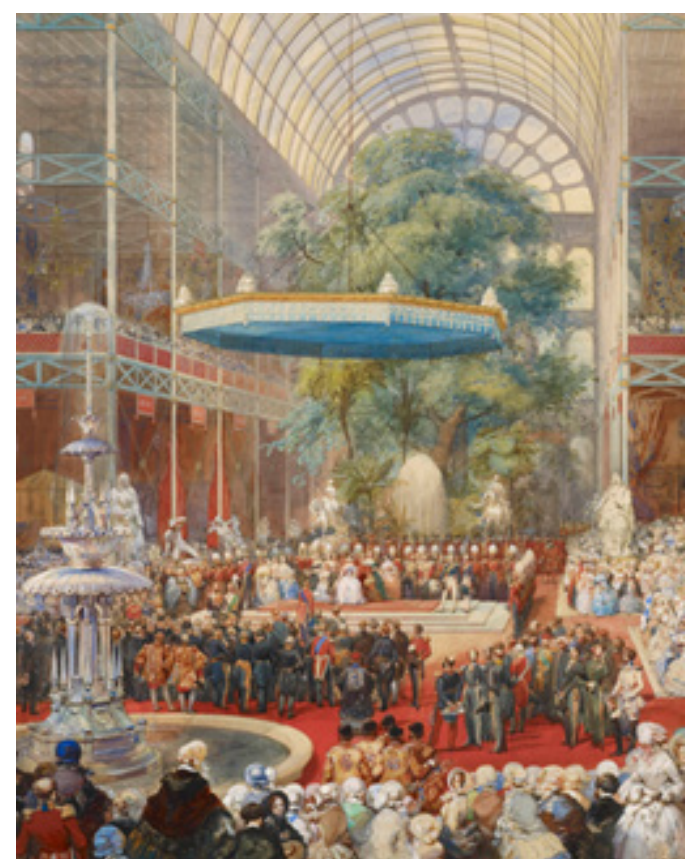

Fonte: Royal Collection Trust (2019).

A respeito do sistema de classificação das exposições universais, Gudehus e Rasmussen (1992) afirmam que a função classificatória tem um papel determinante por duas razões: primeiro, por colocar os objetos em uma ordem, segundo um princípio de afinidades, e depois, porque isto possibilita a comparação dos objetos expostos ao júri. De acordo com a lógica classificatória, que deriva da taxonomia naturalista do século XVIII, cada objeto é descrito pelo lugar que ocupa dentro da série, e no caso das exposições, o lugar ocupado por um objeto determina seu papel no conjunto da atividade humana.

$\mathrm{Na}$ equipe de jurados estavam pessoas do ramo da metalurgia, membros da associação de prateiros de Sheffield e Birmingham (regiões da Inglaterra reconhecidas pela produção de prata), um professor de química, um arquiteto, e um especialista em diamantes. A formação desta equipe de jurados é, por si, um indício da importância da excelência técnica como parâmetro de avaliação, o que se confirma ao observarmos os critérios para premiação, descritos no regulamento geral da Exposição: 
[...] em objetos manufaturados, será considerada a melhoria da utilidade, meIhoria das formas e padrões, ou a alta habilidade de execução, bem como a utilização de novos materiais, e a combinação de materiais, beleza e design, levando em conta seu preço em relação à excelência de produção. (GREAT EXHIBITION, 1852, tradução nossa).

As medalhas concedidas na classe de metais preciosos, da qual a joalheria fazia parte, deixava clara a busca pela inovação. Elkington, Mason and Co recebeu uma Council Medal ${ }^{8}$ por ter introduzido na Inglaterra os processos elétricos de douração e prateamento dos metais. Apresentou uma coleção de objetos de variadas formas e tamanhos, executados em sua maioria em cobre, ou em metal com níquel, coberto com uma camada de prata, através do chamado electrotype process que combinava eletricidade com sal alcalino de ouro ou de prata. O júri recomendou especial medalha a um conjunto de joias de cobre dourado e esmaltado, ornamentado com retratos da família real pintados sobre porcelana. Apesar da aplicação do electro-process não ter passado incólume às críticas de alguns jurados, preocupados com a saúde dos artesãos, devido ao vapor de prata que emanava no processo, outros expositores também foram premiados pelo bom uso do procedimento, bem como pela utilização de ligas metálicas que favoreciam a execução de folhas de metal mais finas, possibilitando melhor trabalho de cinzelamento ${ }^{9}$ em comprometer a aparência do ouro.

A Exposição Universal deveria ser o centro das maravilhas do mundo, e no segmento da joalheira uma das grandes atrações de 1851 foi a exibição do diamante Koh-i-noor, o maior do mundo, com 360 quilates. No Jornal The Illustrated Exhibitor, o convite anunciava: "Este diamante está agora no Hyde Park, e pode ser visto por qualquer trabaIhador do país por 1 shilling" (THE ILLUSTRATED EXHIBITOR, 1851, tradução nossa), reforçando a ideia de que a Exposição seria uma oportunidade única para as massas adquirirem conhecimento.

O Koh-i-noor, apesar de ter "a pureza da água", tinha uma lapidação ruim, principalmente à luz do dia. A solução encontrada foi:

Ele é agora cercado com um tipo de isolamento coberto com um pano vermelho. Toda a luz do dia é retirada do seu interior, e se colocam jatos de gás sobre a gema, em torno da qual estavam posicionados refletores metálicos, fazendo com que o diamante parecesse mais bonito. (THE ILLUSTRATED EXHIBITOR, 1851 b, n.6, p.159, tradução nossa).

Outro grande ganhador de uma Council Medal, a joalheria Garrard, R. and S., and Co, situada no Haymarket, Londres, apresentou uma coleção extremamente rica, provando a imensa extensão da habilidade inglesa nos trabalhos de ouro e prata (GREAT EXHIBITION, 1852). Garrard recebeu muitos elogios do júri pelo bom gosto das suas peças em pérolas, opalas e safiras, bem como pelo tamanho e pureza dos seus diamantes. No relatório, o júri aponta seu veredito: "A pureza e o tamanho de seus diamantes, rubis e pérolas, bem como a qualidade da sua mão de obra, levou o júri a indicar a Casa Garrard ao maior prêmio da Exposição, por conduzir ao progresso a indústria nacional". (GREAT EXHIBITION, 1852, p.513, tradução nossa).

A Casa Garrard foi fundada em 1735 e está em funcionamento até hoje, sendo que, em 1843, recebeu o título de primeira joalheria oficial da Rainha Victoria. A sólida re-

8 A Council Medal era a distinção mais alta oferecida na Exposição de 1851, recomendada para aqueles que demonstravam uma invenção ou inovação que contribuísse para a evolução do setor ao qual pertenciam. As outras categorias de prêmios eram a Prize Medal, para peças com excelência de qualidade e execução, e a Menção Honrosa, para aqueles que apresentavam mérito incontestável, porém sem justificativa para a recomendação de uma medalha.

9 Cinzelamento é uma técnica de trabalhar os metais, que consiste em utilizar ferramentas (cinzel) para dar formas ao metal. 
lação com a Casa Real britânica vem de longa data. Em 1841, a Garrard criou um broche de safira com diamantes, que o Príncipe Albert deu de presente para a Rainha Victoria, para que usasse na cerimônia do casamento como o "seu algo azul"10. Tal broche teria sido a inspiração para que em 1981, exatos 150 anos depois, a própria Garrard criasse o anel de noivado do Príncipe Charles com a Princesa Diana, o mesmo que recentemente voltou à cena real com o noivado do Príncipe William e a Duquesa de Cambridge, em 2010, quando réplicas do anel foram vendidas por toda a Inglaterra, e também no Brasil. Foi também a Casa Garrard responsável pela relapidação do diamante Koh-i-noor, que foi novamente exposto ao público britânico alguns anos mais tarde, na Exposição Internacional, realizada novamente em Londres em 1862. A tradição de mais de duzentos anos de atividades e suas relações com a casa real inglesa ainda hoje têm papel relevante na imagem da empresa, que produz joias inspiradas na joalheria da realeza, e informa aos clientes que a empresa "[...] vem servindo cada monarca britânico desde 1841." (GARRARD, 2019).

Ainda na esteira das novidades da Exposição de 1851, surgem as pérolas artificiais exibidas pelo Sr Constant Valès. Diz o relato do júri:

O juri observou com satisfação as pérolas artificiais exibidas por M. Constant Valès, que demonstrou grande habilidade em superar as dificuldades de execução, e produziu uma imitação superior de pérolas naturais. Eles o premiaram com uma Prize Medal". (GREAT EXHIBITION, 1852, p. 518).

Valès não foi o único a receber prêmios por imitações; o mesmo ocorreu com o joalheiro francês Truchy, que levou uma medalha por apresentar uma perfeita imitação de pérolas negras, além dos Srs. Savary \& Mosbach, também franceses, que levaram medalhas pela qualidade de suas pedras de imitação, principalmente esmeraldas e diamantes. Hunt and Roskel, joalheria britânica fundada em 1843, também recebeu uma Council Medal, por ter apresentado "Um buquê de diamantes, tão rico quanto elegante, do qual podem ser retiradas peças, até as pétalas das flores, para limpeza, ou para transformar em 7 broches. Uma peça que desafia as críticas”. (GREAT EXHIBITION, 1852, p. 513).

Os joalheiros Hunt e Elkington aparecem novamente na Exposição Universal seguinte, realizada em Londres, em 1862, dessa vez como membros do júri, além de expositores. Dizia o regulamento que os expositores que fossem também jurados não poderiam competir na mesma classe da qual fossem avaliadores.

\section{THE INTERNATIONAL EXHIBITION, LONDRES, 1862}

A International Exhibition, foi realizada de maio a novembro de 1862, poucos meses após a morte do Príncipe Albert, que havia sido o Presidente da Exposição de 1851. Desta vez, 25 mil expositores estavam divididos em 4 grandes sessões e 40 classes de produtos, sendo que a joalheria continuou associada aos objetos de metal e outros ligados às artes decorativas, como cerâmica e vidro.

De acordo com matéria publicada em 2014 pela revista inglesa The Decorative Arts Society, sob o título Jewellery at the 1862 Exhibition, havia "um oceano" entre a joia que havia sido apresentada na Exposição Universal de 1851 e a que entraria em cena no evento de 1862. Além de apresentar novamente o diamante Koh-i-noor relapidado para proporcionar maior brilho, a exposição de joias de 1862 foi marcada pelas joias arque10 A tradição surgida na Inglaterra no século XIX, e que depois se espalhou pelos Estados Unidos, diz que toda noiva deve usar algo antigo, algo novo, algo emprestado e algo azul. 
ológicas, camafeus, e peças ao estilo Holbein - que foram assim chamadas por terem sido inspiradas em retratos do pintor alemão Hans Holbein, do século XVI. Esta mudança de gosto teria introduzido uma nova percepção da joalheria, não como commodity, mas como um meio de arte.

Figura 2: Joias estilo Holbein, expostas na Exposição Universal de 1862.

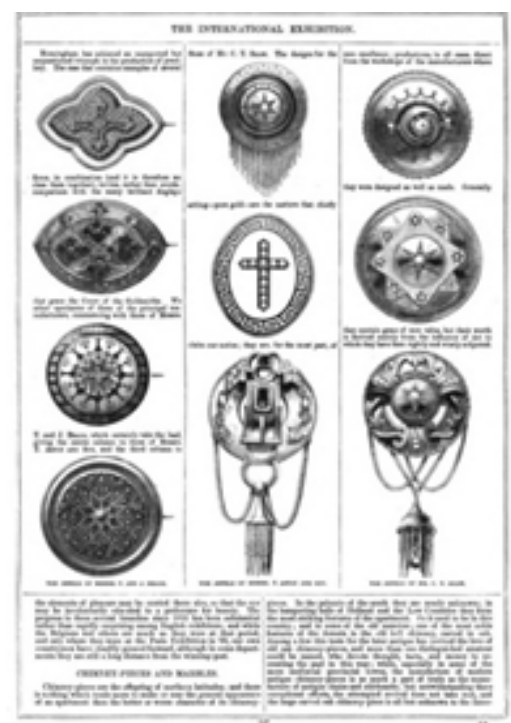

Fonte: The Art Journal Illustrated Catalogue of the International Exhibition, 1862.

\subsection{AS JOIAS ARQUEOLÓGICAS}

As descobertas arqueológicas, ocorridas na década de 1850 , foram responsáveis por espalhar pela Europa o gosto pelas coisas antigas. As joias encontradas nas escavações foram inspiração para que joalheiros ingleses, como Robert Philips, recriassem joias com motivos antigos, e também com o uso de besouros como adornos.

Vale ressaltar que artefatos feitos com besouros, inclusive com espécies originárias do Brasil, já haviam circulado na Exposição de 1851, conforme consta na lista de expositores do Catálogo Geral daquela Exposição: "Major, C.T. Esq. 21 Billiter Street, Londres - folhas e borboletas feitas de asas de besouros, por Henrique José da Silva, Rio de Janeiro". (GREAT EXHIBITION, BRAZIL, p. 208). Alguns anos depois, por ocasião da Exposição de 1876, realizada na Philadelphia, o Império brasileiro produziu um catálogo com o objetivo de promover o país e os produtos nacionais que seriam apresentados na exposição. No capítulo que descreve os insetos, observamos o seguinte: "[...] na ordem dos coleópteros, há insetos que apresentam lustros metálicos e cores variadas, que são empregados na manufatura dos mais bonitos ornamentos, flores, grinaldas, colares, brincos e muitos outros artigos elegantes." (THE EMPIRE..., 1876, p. 43).

As joias que circulavam nas Exposições Universais, que representavam os gostos e ideais da elite europeia, ultrapassavam as fronteiras dos seus locais de origem e alcançavam territórios em outras partes do mundo. No acervo do Museu Paulista, em São Paulo, encontramos um conjunto de joias feitas com besouros, composto por pulseira, abotoaduras, broche e brincos, que remete ao mesmo tipo de besouro de lustro metálico citado no catálogo de 1876. O conjunto não possui marcas, nem foram encontrados até o momento documentos que atestem sua procedência, podendo ter sido trazido da Europa, mas tendo utilizado besouros brasileiros ou ter sido fabricado no Brasil. 
Figuras 3 e 4: Conjunto de joias de besouros em seu estojo e broche do conjunto.
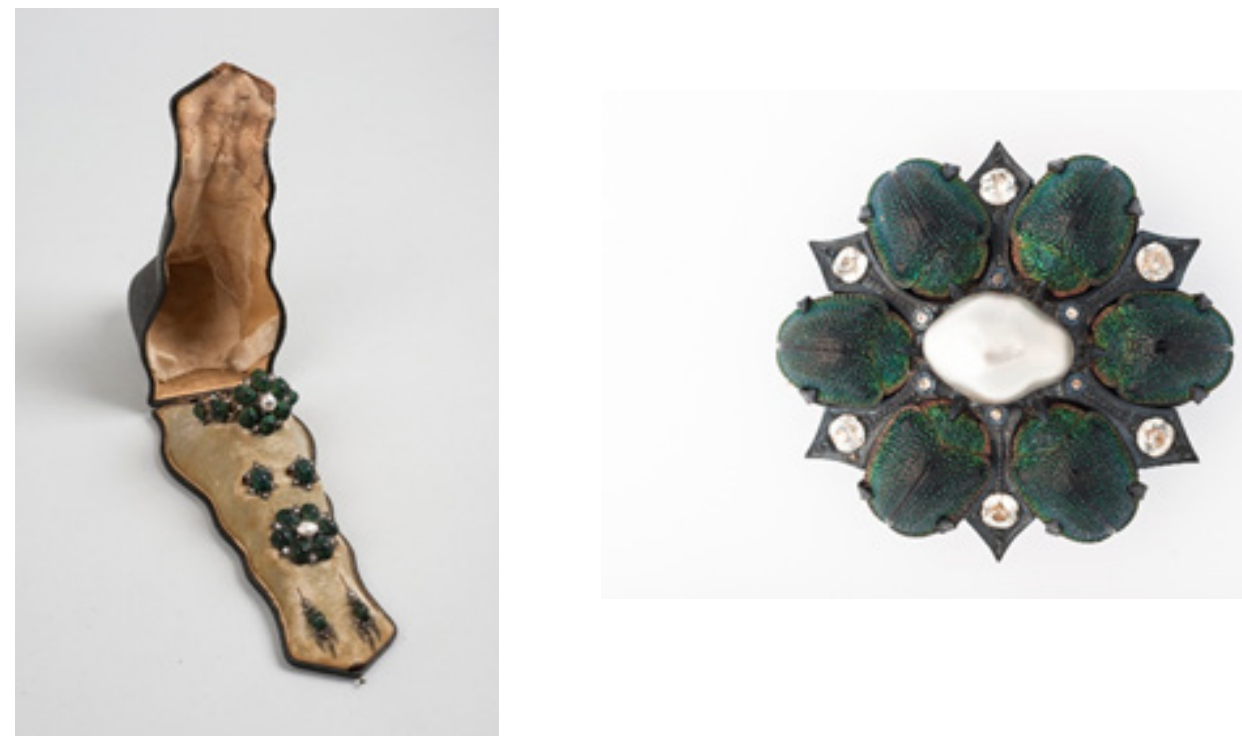

Fonte: Acervo do Museu Paulista. Fotos de Helio Nobre.

\subsection{AS JOIAS DO DUKE DE DEVONSHIRE}

Outra tipologia de joia premiada na Exposição de 1862 foram os camafeus. Faces esculpidas em gemas ou materiais orgânicos, como marfim ou coral, deram à joalheria contornos de arte, onde a habilidade do artista em esculpir era mais apreciada que o valor intrínseco do material.

Os camafeus mais famosos premiados na Exposição de 1862 são os que compõem o conjunto de joias do Duke de Devonshire ${ }^{11}$, composto por 7 peças: pente, stomacher, bandeau, colar, diadema, coroa e bracelete, criado pelo joalheiro londrino Mess. Hancocks \& Co, sob encomenda do então Duke de Devonshire, para que sua sobrinha Condessa de Granville usasse na coroação do Tsar Alexandre II, em Moscou, em 1856. Ao todo, são 88 camafeus esculpidos em safiras, esmeraldas e rubis. Um catálogo especial chegou a ser produzido para descrever detalhadamente o desenho de cada camafeu integrante do conjunto e o que ele representa. O stomacher pertencente ao conjunto chama a atenção pelas suas dimensões, cobrindo praticamente toda a frente do corpete, do peito à cintura. Uma peça rígida com tais dimensões aplicada ao corpete provavelmente limitasse os movimentos do corpo, talvez até impedindo que a pessoa pudesse se sentar. (ILLUSTRATED ..., 1857)

No Brasil também foram usados os camafeus em diferentes materiais. No acervo do Museu Paulista, por exemplo, verificamos dois broches de camafeus, sendo um esculpido em madrepérola, e outro em azeviche ${ }^{12}$, que por ter a cor preta, era provavelmente utilizado como joia de luto.

11 Atualmente, o conjunto de joias de Devonshire faz parte do acervo da Chatsworths House, castelo da família Cavendish, na região central da Inglaterra. Imagens atuais do conjunto de joias do Duke de Devonshire estão disponíveis em: https://www.sothebys.com/en/articles/treasure-of-the-week-the-devonshire-parure

120 Azeviche é uma substância mineral de cor muito negra, que tem origem em um tipo de carvão fossilizado. 
Figura 5 e 6: Broches de madrepérola e ônix.
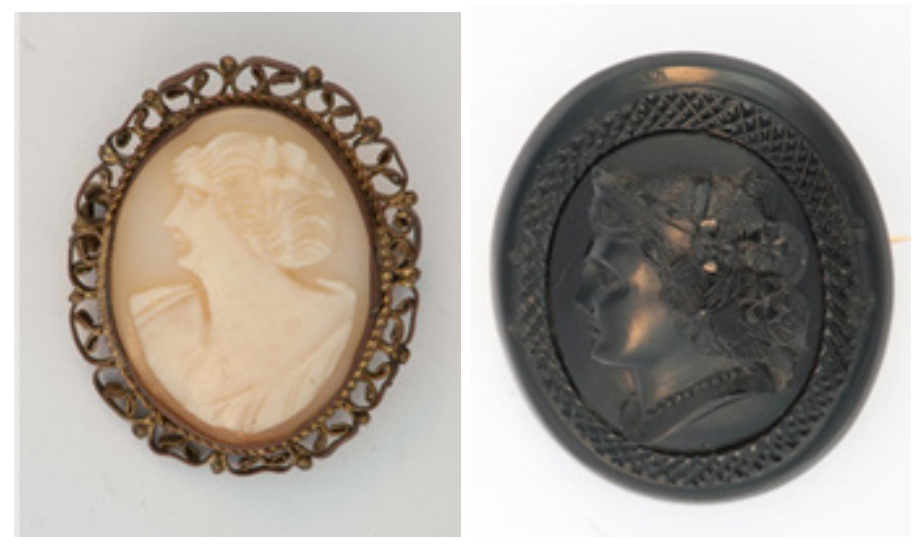

Fonte: Acervo do Museu Paulista. Fotos de Helio Nobre.

As joias de luto tornaram-se populares com a viuvez precoce da Rainha Victória em 1861. A partir da morte do Príncipe Albert, a Rainha, então com 42 anos, usou luto até o fim da vida, em 1901. Joias de luto eram feitas em geral de materiais escuros, como azeviche, ônix e ametistas.

\section{A EXPOSIÇÃO UNIVERSAL DE PARIS, 1889}

Chega o final do século XIX, e a grande atração da Exposição de Paris de 1889 foi a iluminação elétrica, que permitiu que a exposição fosse visitada também durante a noite. No setor de joalheria, o espetáculo das luzes valorizava as vitrines. A Exposição, comemorativa do centenário da Revolução Francesa, reuniu 61 mil expositores, divididos em 9 grupos e 83 classes de produtos.

A joalheria estava na classe denominada Tecidos, Vestimentas e Acessórios, o que indica que a joia estava definitivamente associada à sua função, e não mais à sua matéria prima, como ocorria nas primeiras Exposições, quando o segmento da joalheria estava inserido na classe dos metais.

No relatório do júri percebemos a referência aos termos bijouteria e joalheria, sendo o primeiro relativo às joias feitas em metal dourado ou prateado, e o segundo referente às peças com diamantes e pedras preciosas. A descoberta das minas de diamantes na África do Sul na década de 1870 inundou o mercado europeu desse tipo de pedra e baixou seu preço, passando-se, então, a valorizar um bom desenho feito com arte e perfeitamente executado. Formas de difícil execução eram muito apreciadas: flores e folhagens para cabelo e para indumentária, além de formas fantasiosas como galinhas, borboletas, dragões, sereias e tartarugas. Além disso, a preparação dos metais também deveria ser feita com arte; esmaltes, niellos ${ }^{13}$, filigranas ${ }^{14}$ e mosaicos seriam elementos essenciais para uma boa joia.

Os quatro grandes prêmios da joalheira de 1889 foram para joalheiros franceses. Destes, Mme. Veuve Savard e fils foi premiada por bijuterias de ouro para exportação (produto do qual o Brasil era um dos principais clientes), e MM. Topart et Ruteau receberam igual distinção pela fabricação de excelentes pérolas de imitação.

13 Niello é uma liga metálica de cor negra composta por enxofre, cobre, prata e por vezes chumbo, usada como preenchimento de linhas de contorno em peças de ourivesaria.

14 Filigrana são fios de ouro ou prata que formam desenhos, como rendas. 
Os relatórios oficiais dão conta de que havia grandes esforços para se produzir artificialmente as pedras preciosas, porém "as tentativas existentes ainda estavam restritas aos laboratórios, como M. Feil, que tentou imitar as gemas através da fusão em altas temperaturas dos elementos que as compõem" (PICARD, 1892, p. 549). Entretanto, se as reproduções artificiais ainda não estavam em domínio industrial, as imitações eram objetos de comércio importante. Vidros coloridos por um óxido metálico, apresentando um aspecto análogo às gemas, além do largo uso do strass ${ }^{15}$ no lugar do diamante.

Apesar de termos notícias de imitações de pérolas desde a Exposição de 1851, somente nos relatórios de 1889 o processo de fabricação foi descrito detalhadamente, indicando que se tornara, então, uma prática mais corrente. De acordo com o relatório, pérolas de imitação têm uma enorme produção, seja para a indumentária ou para a joaIheria. Um só fabricante chega a empregar 1.700 pessoas. $O$ documento informa ainda que na Exposição de 1889 foi apresentado um novo método de execução de pérolas falsas:

Vidro com uma camada perolada, mais uma camada de verniz, preenchido com pasta derretida [até então fazia-se o preenchimento com goma arábica ou cera quente]. Este novo método, apesar de proporcionar menor brilho, suporta a imersão em água quente. (PICARD, 1892, p. 549).

Com a joalheria cada vez mais se aproximando do universo das artes, outro francês ganhador do Grand Prix de joalheria foi a então já famosa casa francesa de Frédéric Boucheron, com a qual iniciamos este artigo, que criou um colar totalmente inovador, que não necessitava de fecho, por possuir uma mola escondida que envolve o pescoço, e que assim como uma obra de arte, ganhou até mesmo um título: "Colar Ponto de Interrogação", devido ao seu formato. Depois que o primeiro colar com esse sistema foi apresentado na Exposição Universal de 1889, outros com a mesma forma foram criados pela marca, tornando-se uma peça icônica da Maison Boucheron. (BOUCHERON, [201?]).

\section{CONCLUSÃO}

Com o objetivo de contribuir para uma aproximação interdisciplinar da história da moda, dedicamos este artigo a refletir sobre as fontes para estudo da joalheria do século XIX a partir da perspectiva da cultura material. Utilizamos como objeto de análise fontes textuais e visuais sobre as Exposições Universais da segunda metade do século XIX, visto que as Exposições tinham, entre outras funções, o papel disseminador de gostos, ideias e hábitos reinantes entre a elite europeia, que acabavam por se espalhar por outros territórios, chegando, inclusive, ao Brasil.

Analisamos os relatórios dos júris das classes de joalheria das Exposições realizadas em Londres em 1851 e 1862, e também em Paris em 1889, a partir dos quais buscamos identificar os critérios para premiar as joias expostas.

Identificamos, primeiramente, que a formação da equipe de jurados atesta a preocupação constante da organização das exposições com as questões técnicas e de inovação. Na primeira grande exposição universal realizada em Londres, em 1851, os prêmios mais altos da categoria foram recomendados para os joalheiros que desenvolveram os processos de douração eletromagnética dos metais, recurso que possibilitava o barateamento das peças. Joalheiros que tinham tradição e proximidade com a casa real britânica também se destacaram na exposição, não só pela opulência das peças

15 Strass são pedras de vidro revestidas com metal na parte inferior, para imitar o brilho do diamante. 
apresentadas, que em muitos casos eram de propriedade de nobres ingleses ou mesmo da Rainha Victoria, mas também, pela pureza dos diamantes e o equilíbrio entre o tamanho das gemas e a quantidade dos metais que compunham as joias, ao que o júri chamou de leveza.

Os anos seguintes à Exposição de 1851 foram um período de importantes descobertas arqueológicas no Egito, fazendo surgir o gosto pelas joias da antiguidade. $O$ joalheiro inglês Robert Philips foi protagonista no desenvolvimento da chamada joia arqueológica, inspirada em joias egípcias, que utilizavam besouros na sua confecção. As joias arqueológicas foram destaque na Exposição Universal de 1862, realizada também em Londres, juntamente com os camafeus - joias de materiais orgânicos esculpidas com figuras da antiguidade, além do chamado Holbein Style, inspirado em retratos do pintor do século XVI Hans Holbein.

Apesar de identificarmos que os critérios de premiação variavam de uma exposição para outra, podemos observar uma tipologia de joia que recebeu prêmios em todas as exposições do século XIX: as imitações, tanto de pérolas como de gemas coradas, fizeram sucesso por serem bem executadas e, assim como os processos de douração dos metais, barateavam as joias.

Já no final do século XIX, na Exposição de 1889 em Paris, a primeira exposição com iluminação elétrica, o grande destaque da joalheria foi para o espetáculo das luzes, já que era possível iluminar as vitrines de forma a potencializar o brilho dos diamantes. A joia ganhou contornos de obra de arte, onde o desenho, a forma e a excelência da execução passaram a ser fundamentais. Neste contexto, a joalheria francesa Boucheron levou o Grand Prix de 1889 com o "colar Ponto de Interrogação", o primeiro colar confeccionado sem fecho, que veio a se tornar peça icônica da marca.

\section{REFERÊNCIAS}

BOUCHERON. [2019]. Disponível em: https://us.boucheron.com/en_us/the-maison/history.html. Acesso em 06 set. 2019.

GERE, Charlotte; RUDOE, Judy. Jewellery at the 1862 exhibition. The Journal of the Decorative Arts Society 1850 - the Present, n.38, 2014, p. 82-105.

GREAT EXHIBITION LONDON. Official catalogue of the great exhibition of the works of industry of all nations, 1851. London: Spicer brothers, 1851a. https://catalog.hathitrust.org/Record/011633058/Home. Acesso em 06 set. 2019.

GREAT EXHIBITION LONDON. Reports by the juries on the subjects in the thirty classes into which the exhibition was divided. London: Spicer Brothers; wholesale stationers; 1852. Disponível em: https://catalog.hathitrust.org/Record/100234836/Home. Acesso em 06 set. 2019.

GREAT EXHIBITION LONDON. The Illustrated Exhibitor: a tribute to the world's industrial jubilee. London: J. Cassell, 1851b. Disponível em: https://babel.hathitrust.org/cgi/ pt?id=uc1.31175001860983\&view=1up\&seq=159. Acesso em 06 set. 2019.

ILLUSTRATED AND DESCRIPTIVE CATALOGUE OF THE CELEBRATED DEVONSHIRE GEMS, 1857. Disponível em https://archive.org/details/CatalogueDevonshireGems/ page/n4. Acesso em 06 set. 2019.

JORNAL CORREIO PAULISTANO. Edição 0472, Ano 1867. Disponível em bndigital. bn.br/acervo-digital/correio-paulistano/090972. Acesso em 06 set. 2019. 
JULIEN, Marie-Pierre; RUSSELIN, Céline. La culture matérielle. Paris: Éditions La Découverte, 2005.

MALLARMÉ, Stéphane. La Dernière mode: gazette du monde e de la famille. Tradução de Izabel Haddad. Revista Dobras, Paris, v. 9, n. 20, 2016. Disponível em https://dobras. emnuvens.com.br. Acesso em 06 set. 2019.

MENESES, Ulpiano Bezerra de. Memória e cultura material: documentos pessoais no espaço público. Estudos Históricos, Rio de Janeiro, v.11, n. 21, p. 89-104, 1998.

ORY, Pascal. Les expositions universelles, de 1851 à 2010: les huit fonctions de la modernité. In: MEI, Duanmu; TERTRAIS, Hugues (orgs.). Temps croisés I. Paris: Maison des Sciences de l'homme, 2010. p. 225-233.

PESAVENTO, Sandra Jatahy. Exposições universais: espetáculos da modernidade do século XIX. São Paulo: Hucitec, 1997.

PICARD, Alfred. Exposition universelle internationale de 1889 à Paris: rapport général par M. Alfred Picard. Mobilier, tissus, vêtements. Paris: Impr. nationale Paris, 1892. Disponível em: https://gallica.bnf.fr/ark:/12148/bpt6k56566972.textelmage. Acesso em 06 set. 2019.

ROYAL COLLECTION TRUST. 2019. Disponível em https://www.rct.uk/collection/search\#/17/collection/452380/the-opening-of-the-great-exhibition-1851. Acesso em 06 set. 2019.

SCHLERETH, Thomas J. Material culture: a research guide. Kansas: University Press of Kansas, 1985.

SCHROEDER-GUDEHUS, Brigitte; RASMUSSSEN, Anne. Les fastes du progrès: le guide des expositions universelles, 1851-1992. Paris: Flammarion, 1992.

SOUZA, Gonçalo de Vasconcelos e. Percursos da joalheria em Portugal: século XVIII a XX. 2010.

THE ART JOURNAL ILLUSTRATED CATALOGUE OF THE INTERNATIONAL EXHIBITION, 1862. London: J.S. Virtue, 1862. Disponível em https://babel.hathitrust.org/cgi/ pt?id=njp.32101078300884\&view=1up\&seq=175. Acesso em: 06 set. 2019.

THE EMPIRE OF BRAZIL AT THE UNIVERSAL EXHIBITION OF 1876 IN PHILADELPHIA. Rio de Janerio: Typ. e lithographia do Imperial Instituto Artistico, 1876. Disponível em: https://hdl.handle.net/2027/mdp.39015028000316. Acesso em 06 set. 2019.

Recebido em: 30/07/2019

Aceito em: 06/09/2019

DOI: http://dx.doi.org/10.5965/25944630332019054 